\title{
Restriction enzyme analysis of cytomegalovirus DNA to study transmission of infection
}

\author{
CATHERINE S PECKHAM,* AJ GARRETT, $\dagger$ KS CHIN,* PM PREECE,* \\ D B NELSON,* DIANE E WARREN, $\dagger$
}

From the *Departments of Community Medicine and Paediatrics, Charing Cross and Westminster Medical School, London, and $\uparrow$ National Institute for Biological Standards and Control, London

SUMMARY Restriction enzyme analysis of cytomegalovirus deoxyribonucleic acid (DNA) has been used to characterise virus isolates and has provided information on patterns of viral transmission.

It was shown that virus isolated from a congenitally infected infant was unlikely to have originated from the 13 congenitally infected children with whom the mother, a nurse, had been in contact. Of nine mother and infant pairs, from whom cytomegalovirus was isolated, seven yielded strains that were indistinguishable for mother and child; one pair showed minor differences and one was clearly distinguishable. Virus isolates from seven children attending a day nursery were typed, and only siblings were excreting similar strains of cytomegalovirus. Further examples of the application of this technique to studies of cytomegalovirus in a family environment are given.

It is concluded that characterisation of virus strains by restriction analysis of DNA is a valuable epidemiological tool.

Cytomegalovirus infection during pregnancy and in the immunosuppressed patient can have serious

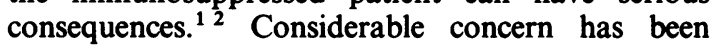
expressed that infection may spread to nursery school teachers, nurses, and medical personnel who may be in close contact with infected subjects. ${ }^{34}$ In the course of our studies on the consequences of congenital cytomegalovirus infection, ${ }^{5}$ and the prevalence of acquired infection in infants as well as in children attending day nurseries, it became clear that there was a need for a readily applicable technique for typing strains of cytomegalovirus to identify patterns of transmission of infection. The source of cytomegalovirus infection cannot be determined unequivocally by serology or by isolation of the virus from epidemiologically related cases. Restriction enzyme analysis of DNA for identifying different strains of cytomegalovirus was first developed by Huang et al. ${ }^{6}$ More recently, Garrett and Warren described a modification of this technique that is simpler and requires smaller quantities of virus. ${ }^{7}$ The application of this modified method, which is applicable for routine use in large epidemiological surveys, is shown in this paper.

Accepted for publication 14 November 1985

\section{Subjects and methods}

The subjects reported were derived from several different sources: a congenitally infected infant born to a nurse who had been in contact with 13 children with cytomegalovirus infection during her pregnancy; a family study; seven children excreting cytomegalovirus in a day nursery; and nine mother and infant pairs from whom the virus was isolated. Isolates of cytomegalovirus grown from throat swabs, urine, or breast milk were stored in liquid nitrogen. They were subsequently regrown in culture bottles containing $25 \mathrm{~cm}^{2}$ sheets of human embryo lung fibroblasts and incubated at $36-37^{\circ} \mathrm{C}$.

The method for differentiation of cytomegalovirus strains by restriction enzyme nuclease analysis of virus DNA has been described in detail by Garrett and Warren. ${ }^{7}$ In brief, cultures infected with cytomegalovirus were labelled with ${ }^{32} \mathrm{P}$, and crude DNA was extracted and digested with restriction endonuclease (EcoRI, Bam H1, Bgl II, or Hind III). The resultant oligonucleotides were separated by electrophoresis on agarose gels. As a reference for each digest and each electrophoretogram, the appropriate DNA digest from cytomegalovirus strain Ad 169 was 
Cytomegalovirus serological state* IgM†

\begin{tabular}{|c|c|c|c|c|c|}
\hline Index case & & & & & \\
\hline Father & & & & & $\Delta \mathrm{A}$ \\
\hline Mother & $\Delta$ & $\Delta$ & $\Delta$ & $\Delta \mathbf{P}$ & $\Delta \mathbf{P}$ \\
\hline
\end{tabular}

Virus isolation **

\begin{tabular}{|c|ccccc|}
\hline Index case & 0 & $\bullet$ & $\bullet$ & $\bullet$ & $\bullet$ \\
\hline Father (30) & & & & 0 & 0 \\
\hline Mother (27) & & 0 & 0 & 0 & 0 \\
\hline Sibling 1 (7) & & 0 & 0 & 0 \\
\hline $2(5)$ & & 0 & 0 & $\bullet$ \\
\hline $3\left(3 \frac{1}{2}\right)$ & & 0 & $\bullet$ & $\bullet$ \\
\hline $4(2)$ & & 0 & $\bullet$ & 0 \\
\hline
\end{tabular}

Blood

transfusions ||||||

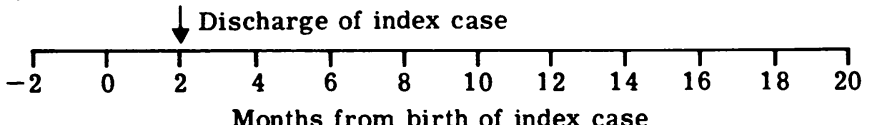

\footnotetext{
* CMV Complement fixation test $\Delta<5$

$\Delta 20$

** Virus isolation o negative

- positive

+ IgM A absent

P present

( ) Parental and sibling age in years
}

Fig. 1 Family study of acquisition of cytomegalovirus

included. At least three different enzyme digests were used to distinguish the similarity or dissimilarity of oligonucleotide maps of each epidemiologically related virus. The isolates were tested blind by AJG and DEW.

Isolates obtained sequentially from children with congenital cytomegalovirus or acquired infection showed no change in DNA maps with time, and no change in pattern was observed in other isolates passaged as many as $\mathbf{4 0}$ times.

\section{Results}

CONGENITAL CYTOMEGALOVIRUS IN THE

INFANT OF A NURSE EXPOSED TO

INFECTED CHILDREN DURING HER

PREGNANCY

A nurse who had worked in a clinic where children with congenital cytomegalovirus were being studied seroconverted in late pregnancy, three weeks after she ceased to work. She subsequently delivered an infant with congenital cytomegalovirus who was asymptomatic and developing normally at nine months. No cytomegalovirus was isolated from the nurse, but virus grown from her infant and from all 13 con- genitally infected children who had attended the clinic during the last six weeks of her employment were typed. All had dissimilar DNA patterns showing that none of the children with whom the nurse had been in contact was the source of her child's infection.

\section{FAMILY STUDY}

In a family study, the index child acquired cytomegalovirus infection while in a special care baby unit. Two intrauterine blood transfusions had been given at 26 and 28 weeks' gestation for Rhesus isoimmunisation, and the baby was delivered by elective caesarean section at 30 weeks' gestation. After birth the infant received three exchange transfusions in the first 48 hours and three further transfusions of $20-35$ $\mathrm{ml}$ each. The last two transfusions were from cytomegalovirus seropositive donors. Congenital infection was excluded as the infant was initially cytomegalovirus seronegative, and no virus was isolated from urine samples collected in the first few weeks of life. Cytomegalovirus was first isolated from urine at 60 days, which was compatible with acquisition of infection from blood transfusion. The infant was discharged aged 10 weeks and continued to shed virus in the urine. 


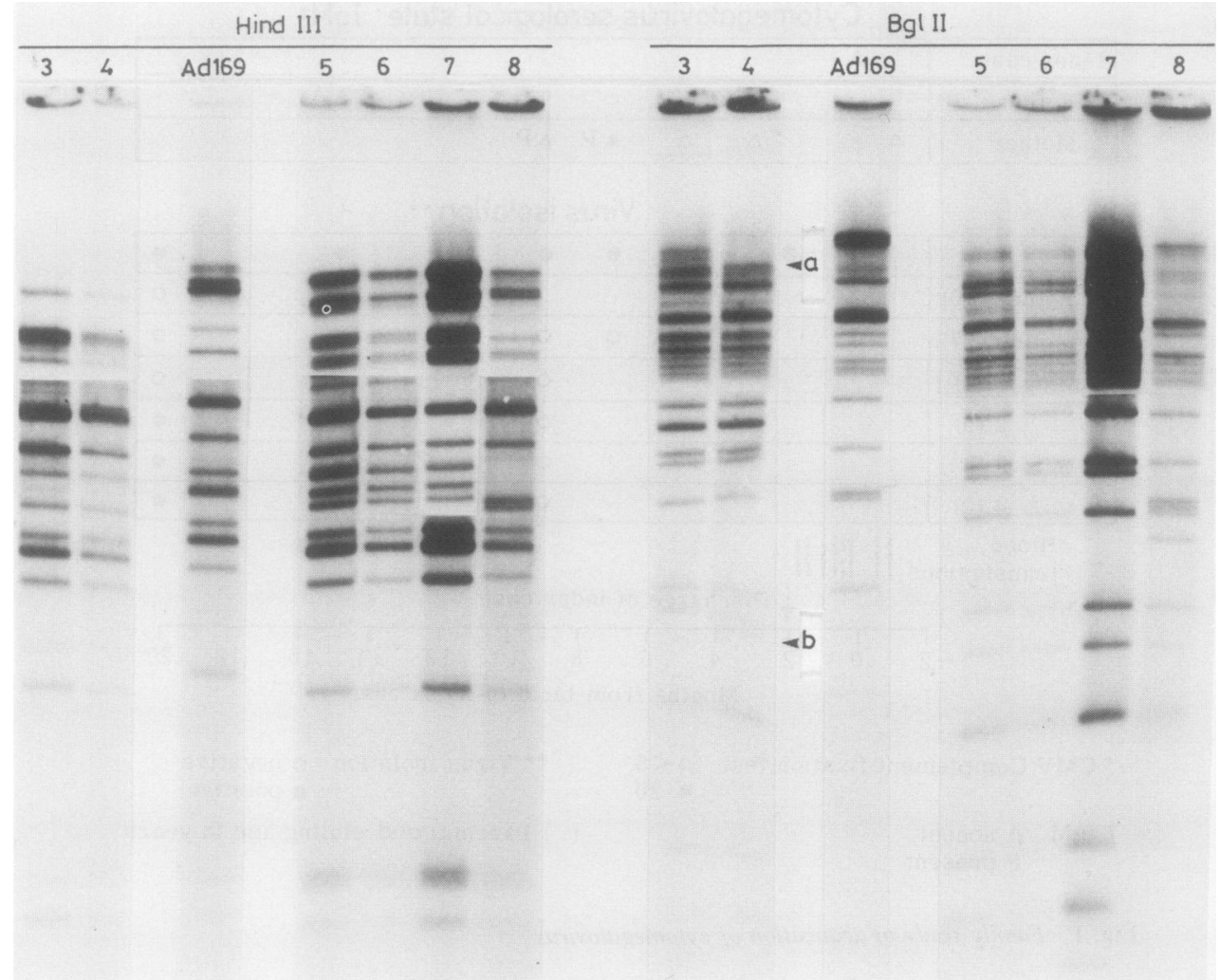

Fig. 2 Oligonucleotide patterns of cytomegalovirus DNA from family study. DNAs were digested with Hind III and Bgl II; lane 3, virus from infant's urine; lane 4, virus from mother's breast milk; lanes 5,6,7, viruses from three siblings in family study; lane 8 , virus from index case in family study.

Fig. 1 shows details of the index child and family. Serum collected from the mother during the antenatal period showed no cytomegalovirus complement fixing antibodies, but seroconversion had occurred by the time the infant was 8 months old. Cytomegalovirus specific IgM was detected at this time and persisted for two months. As IgM is present for up to four months after primary cytomegalovirus this suggests a recent infection. ${ }^{8}$ Repeated attempts to grow virus from urine and throat swabs were unsuccessful. The father was initially seronegative but seroconverted after 16 months' exposure to the index child. Cytomegalovirus specific IgM was not present in this blood sample, suggesting that infection had been acquired 8-12 months after initial exposure. No virus could be isolated from the urine despite repeated attempts. Urine samples were obtained from the four older children, and three became infected with cytomegalovirus, two after 14 months' and one after 18 months' exposure.

In this family study, genetic maps of the isolates from the four children after digestion with EcoR1, Bgl II, and Hind III were examined (Fig. 2). The oligonucleotide patterns of the viruses grown from the three older siblings (lanes 5-7) were indistinguishable and clearly different from that of the virus isolated from the index case (lane 8). This suggests that despite continued excretion of virus in the urine of the index case infection in the older children had been acquired from another source. As virus could not be isolated from the parents it was impossible to determine the source of their infections.

\section{CHILDREN ATTENDING A DAY NURSERY}

In this day nursery urine samples were collected every three months. Virus was isolated from nine children and, over a year, $18 \%$ were excreting cytomegalovirus at any one time. Virus isolates for seven children were typed, and Fig. 3 shows the oligonucleotide patterns of virus grown from five children. None of these virus isolates was similar to any other (lanes 9-13), indicating that the source of infection was different for 


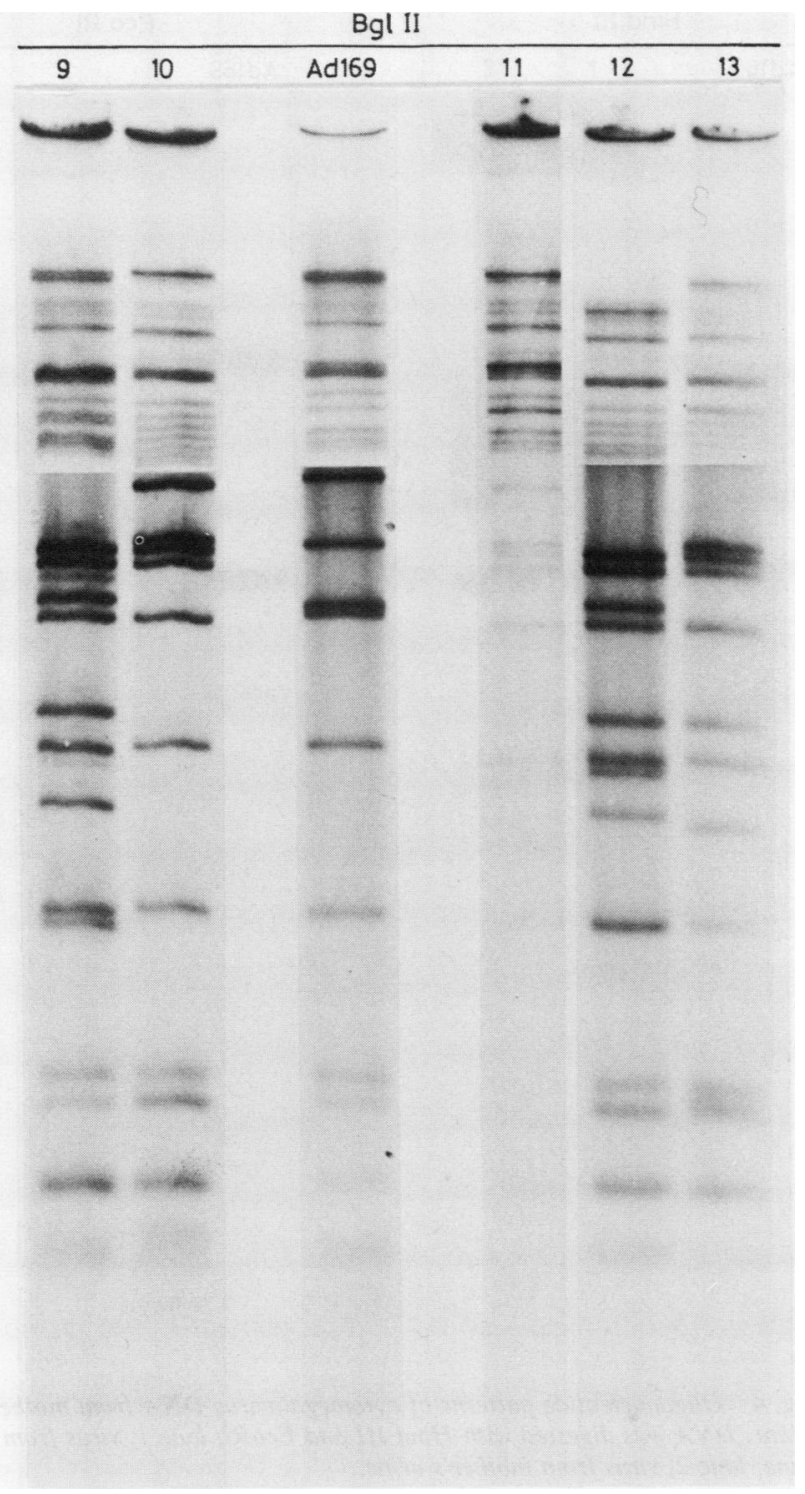

Fig. 3 Oligonucleotide patterns of cytomegalovirus DNA from children attending same nursery school; lanes 9,10,11,12,13, virus from urine.

each case. Two other children attending this school were excreting virus that could not be differentiated by endonuclease analysis; it was noteworthy that they were siblings.

NINE MOTHER AND INFANT PAIRS

In all nine cases in which cytomegalovirus was grown from both the infants and their mothers the isolates were typed. Fig. 4 shows the similarity of oligonucleotide patterns of cytomegalovirus isolates grown from a mother's urine (lane 1) and from the urine of her 3 month old infant (lane 2) after digestion with Hind III and EcoR1, using Ad 169 as a control for the digest conditions. This infant acquired cyto- 


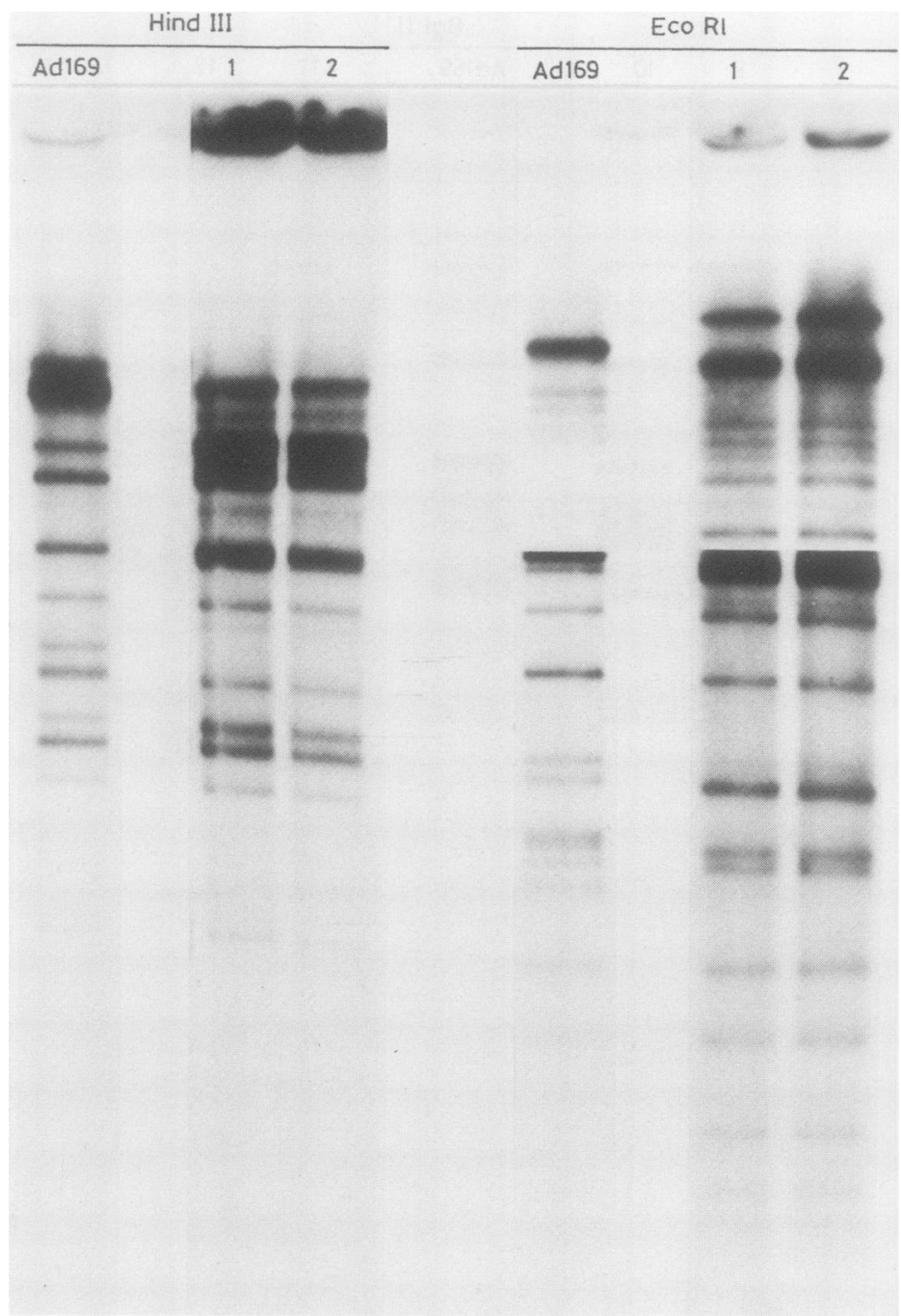

Fig. 4 Oligonucleotide patterns of cytomegalovirus DNA from mother and infant. DNA was digested with Hind III and EcoRl; lane 1, virus from infant's urine; lane 2, virus from mother's urine.

megalovirus while in a special care baby unit and the close similarities between the restriction maps of the strains suggest transmission of infection from mother to child, probably during birth. The infant had not been breast fed but had received cytomegalovirus seropositive blood and had been in the unit at the same time as another infant who was excreting cytomegalovirus with a dissimilar DNA pattern.

Virus isolates grown from the urine of eight other infants, of whom four had congenital infection and four acquired cytomegalovirus infection in early life, were also typed together with isolates from their mothers' breast milk or urine, or both. The oligonucleotide patterns from cytomegalovirus strains grown from six of these mother and infant pairs could not be distinguished using a minimum of three enzyme digests, thus showing that transmission is likely to have occurred from mother to infant. One pair, in whom virus was isolated from an infant's urine and mother's breast milk, showed minor differences in the patterns of Bgl II digest. Lanes 3 and 4 of Fig. 2 show the similarity of strains after 
digestion with Hind III and the differences that emerged after digestion with Bgl II. The presence of the two additional bands in the high molecular weight region (a) and concomitant deletion of a fragment of about $2.5 \times 10^{6}$ molecular weight (b) was shown in three separate digestions of strains 3 and 4 . Dissimilarity of the virus strains was seen for only one mother and infant pair; virus was first isolated from the infant at 8 months and from the mother's milk for the first time at 18 months, suggesting an alternative source of infection.

\section{Discussion}

Cytomegalovirus infection is usually an asymptomatic or mild infection but it can result in serious consequences when acquired by immunosuppressed patients or pregnant women. ${ }^{12}$ As infants with both acquired and congenital infection continue to shed virus in their urine for many years, concern has been expressed about the risk of young female staff acquiring the infection from children they care for, particularly from children with congenital cytomegalovirus who are known excretors. ${ }^{34}$ Similarly, when a seronegative infant is infected with cytomegalovirus after blood transfusion the mother is thought to be at risk of acquiring cytomegalovirus from the child at the time of her next pregnancy. ${ }^{9}$ Information on the mode of transmission of cytomegalovirus is largely anecdotal or based on circumstantial evidence including the age of acquisition of cytomegalovirus antibodies, the prevalence of cytomegalovirus antibodies in a population, and the knowledge that virus can be isolated from the nasopharynx, genital tract, and semen.

Several workers have shown the value of restriction endonuclease analysis of cytomegalovirus DNA for determining likely transmission of infection. ${ }^{1011}$ There are innumerable genetic variants of cytomegalovirus and restriction enzyme cleavage of cytomegalovirus DNA obtained from random clinical isolates indicates that no two viruses give identical DNA fragments when multiple digests are compared. ${ }^{10}$ In contrast, epidemiologically related cytomegalovirus strains such as those from mother and infant pairs have identical restriction mapping patterns. Our results confirm the high degree of genetic variability among cytomegalovirus strains. Although, routinely, three or four enzymes are used to characterise each isolate, isolates from epidemiologically unrelated cases usually differ sufficiently for differentiation to be established by examination of the digestion products of one endonuclease. Given the large size of the genome, identity of DNA structures is more difficult to establish unequivocally as only about $0 \cdot 1 \%$ of the viral genome is specifically selected by each endonuclease.

More information is required about the effects of transmission of cytomegalovirus to a new host and of periods of latency and reactivation on the stability of viral DNA. The finding that DNA restriction enzyme typing of cytomegalovirus isolates from sex partners showed common strains suggests that the genome does not undergo major mutation after transmission to a new host, ${ }^{12}$ but this needs further study as minor differences have been observed in mother and infant pairs. Mutation, selection of variants, or recombination with reactivated virus could theoretically occur, but this was not shown to be the case when mixed infections were studied in vitro (Garrett AJ, Warren DE, unpublished observations, 1984). Under the conditions described in this paper no genetic variants were detected after clinical isolates were passaged up to 40 times and Ad 169 passaged 100 times in vitro. Huang et al cloned and subcultivated strains Ad 169 and Towne for over 100 passages and discovered only minor modifications in restriction enzyme sites and overall homology with the parental virus retained. ${ }^{13}$

In this study cytomegalovirus isolates recovered from seven of nine mother and infant pairs were identical. In one pair minor differences similar to those reported by Huang were observed. These differences were quite distinct from the major differences seen between epidemiologically unrelated strains of cytomegalovirus. Although repeat digests were performed, the possibility of incomplete digestion could not be excluded. Major differences in DNA patterns were found in only one mother and infant pair, but in this case virus was first isolated from breast milk 10 months after the infant had become infected. It is known that different strains of herpes simplex virus can be shed simultaneously from different sites of the same host, ${ }^{14}$ but there is, as yet, little evidence to suggest that this occurs with cytomegalovirus. Different strains of cytomegalovirus isolated from different sites at the same time were, however, reported in two patients with the acquired immune deficiency syndrome. ${ }^{15}$

Endonuclease analysis of cytomegalovirus isolates from unrelated children attending a day nursery showed no genetic identities, thus showing a lack of horizontal transmission of infection among these children. There was, however, genetic identity of cytomegalovirus from each of two sibling pairs within the same nursery compatible with infection originating in the home. A detailed prospective epidemiological study of cytomegalovirus transmission within a day nursery examining virus isolates from children and staff is in progress to elucidate further the mode of virus transmission and establish whether this poses an important occupational risk. 
From examination of virus DNA of cytomegalovirus isolates from the mother and her infant in special care nosocomial transmission of infection was excluded. Had this not been done the source of infection may have been incorrectly ascribed to contact within the special care unit, and such a conclusion would have had major implications for management and infection control. In the past nosocomial transmission has often been assumed on the basis of circumstantial evidence. For example, Gurevich and Cunha concluded that cytomegalovirus was transmitted in a neonatal intensive care unit from an infant with congenital cytomegalovirus who had lived only eight hours. ${ }^{16}$ Such a conclusion is unwarranted as analysis of viral DNA was not carried out. Spector, however, analysed cytomegalovirus isolates from seven infants in an intensive care unit and found that the DNA patterns were similar in three. ${ }^{17}$ This is the only published evidence of cytomegalovirus transmission among infected babies.

As in other studies in which restriction enzyme analysis was possible, temporal associations of cytomegalovirus infection in adults caring for infected infants failed to show a causal link, ${ }^{18-21}$ suggesting that infection had been acquired outside the hospital. As yet there have been no reports of the acquisition of cytomegalovirus by staff from known excretors in their care.

We thank all the doctors, nurses, and nursery school staff who made this study possible, Dr K Pearl and Miss C Johnson for their help, Mrs EG Hogben for preparing the manuscript, and Dr G Schild for his useful comments. The work was supported by grants from The National Fund for Research into Crippling Diseases, the Medical Research Council and the Harrison Trust.

\section{References}

${ }^{1}$ Preece PM, Pearl KN, Peckham CS. Congenital cytomegalovirus infection. Arch Dis Child 1984;59:1120-6.

${ }^{2}$ Ho M. Virus infection after transplantation in man: brief review. Arch Virol 1977;55:1-24.

${ }^{3}$ Yeager AS. Longitudinal serological study of cytomegalovirus infections in nurses and in personnel without patient contact. $J$ Clin Microbiol 1975;2:448-52.

${ }^{4}$ Friedman HM, Lewis MR, Nemerofsky M, Plotkin SA. Acquisi- tion of cytomegalovirus infection among female employees of a pediatric hospital. J Pediatr Infect Dis 1985;3:233-5.

${ }^{5}$ Peckham CS, Chin KS, Coleman JC, et al. Cytomegalovirus infection in pregnancy: preliminary findings from a prospective study. Lancet 1983;i:1352-5.

${ }^{6}$ Huang ES, Kilpatrick BA, Huang YT, et al. Detection of human cytomegalovirus and analysis of strain variation. Yale $J$ Biol Med 1976;49:29-43.

${ }^{7}$ Garrett AJ, Warren DE. A simple technique for endonuclease mapping of cytomegaloviruses. J Virol Methods 1985;10:187-94.

${ }^{8}$ Griffiths PD. The presumptive diagnosis of primary cytomegalovirus infection in early pregnancy by means of a radioimmunoassay for specific-IgM antibodies. Br J Obstet Gynaecol 1981;88:582-7.

${ }^{9}$ Yeager AS. Transmission of cytomegalovirus to mothers by infected infants: another reason to prevent transfusion-acquired infections. Pediatr Infect Dis 1983;2:295-7.

${ }^{10}$ Huang ES, Alford CA, Reynolds DW, et al. Molecular epidemiology of cytomegalovirus infections in women and their infants. N Engl J Med 1980;303:958-62.

${ }^{11}$ Spector SA, Spector D. Molecular epidemiology of cytomegalovirus infections in premature twin infants and their mother. Pediatr Infect Dis 1982;1:405-9.

${ }^{12}$ Handsfield HH, Chandler SM, Caine VA, et al. Cytomegalovirus infection in sex partners: evidence for sexual transmission. $J$ Infect Dis 1985;151:344-8.

${ }^{13}$ Huang ES, Hung SM, Tegtmeier GE, Alford CA. Cytomegalovirus: genetic variation of viral genome. Ann NY Acad Sci 1980;354:332-46.

${ }^{14}$ Buchman TG, Roizman B, Nahmias AJ. Demonstration of $\overrightarrow{\mathscr{O}}$ exogenous genital re-infection with herpes simplex virus type 2 ᄋ by restriction endonuclease fingerprinting by viral DNA J Infect Dis 1979;140:295-304.

${ }^{15}$ Spector SA, Hirata KK, Neuman TR. Identification of multiple cytomegalovirus strains in homosexual men with acquired immunodeficiency syndrome. J Infect Dis 1984;150:953-6.

${ }^{16}$ Gurevich I, Cunha BA. Non-parental transmission of cytomegalovirus in a neonatal intensive care unit. Lancet 1981;ii: 222-4.

${ }^{17}$ Spector SA. Transmission of cytomegalovirus among infants in hospital documented by restriction-endonuclease-digestion analyses. Lancet 1983;i:378-81.

${ }^{18}$ Grillner L, Blomberg I. Restriction enzyme analysis of human cytomegalovirus using DNA extracted from infected cells. J Med Virol 1984;14:313-22.

${ }^{19}$ Yow MD, Lakeman AD, Stagno S, et al. Use of restriction enzymes to investigate the source of a primary cytomegalovirus infection. Pediatrics 1982;70:713-6.

${ }^{20}$ Wilfert CM, Huang ES, Stagno S. Restriction endonuclease analysis of cytomegalovirus deoxyribonucleic acid as an epidemiological tool. Pediatrics 1982;70:717-24.

${ }^{21}$ Dworsky M, Lakeman A, Stagno S. Cytomegalovirus transmission within a family. Pediatr Infect Dis 1984;3:236-8.

Requests for reprints to: Professor CS Peckham, Institute of Child Health, 30 Guilford Street, London WCIN 1EH, N England.

(1)

